\title{
Mineralogical evidence for intermittent shallow ocean oxygenation in the aftermath of the Marinoan glaciation
}

\author{
LiAngXUAN JiaO $^{1}$, Zhenbing ShE ${ }^{1}$, DOMINIC PAPINEAU ${ }^{2}$
}

${ }^{1}$ School of Earth Sciences, China University of Geosciences, Wuhan 430074, China

${ }^{2}$ Department of Earth Sciences, University College London, Gower Street, London WC1E 6BT, UK

The Doushantuo Fm (ca. 635-551 Ma) in South China is one important object to study the oxidation events in Ediacaran ocean ${ }^{[1,2]}$. Lack of mineralogical record makes it difficult to confirm timing and meaning of these ocean oxidation events ${ }^{[3]}$. Here we report a flowerlike structure (Fig. 1) with pyrite as core, marcasite as petals, several minerals as filling materials, that are hereon referred to as PyriteMarcasite Rosettes (PMRs), occurring in the lower part of Doushangtuo Fm (Weng'an, South China). As pyrite generally forms from aqueous solutions with $\mathrm{pH}$ of $6 \sim 7$, whereas marcasite growth is favored at $\mathrm{pH}$ of $4 \sim 5^{[4]}$, considering that the aqueous pyrite oxidation can lead to drop of $\mathrm{pH}^{[5]}$, the formation of the PMRs is interpreted as a result of pore water acidification caused by pyrite oxidation. Pulsed oxygenation of the phospogenic shallow ocean likely has resulted in rises of $\mathrm{O}_{2}$ in the bottom water and surfacial sediments, which in turn led to the oxidation of previously formed pyrite ${ }^{[6]}$. The Doushantuo PMRs thus provide evidence for intermittent shallow ocean oxygenation events after the Marinoan glaciation.

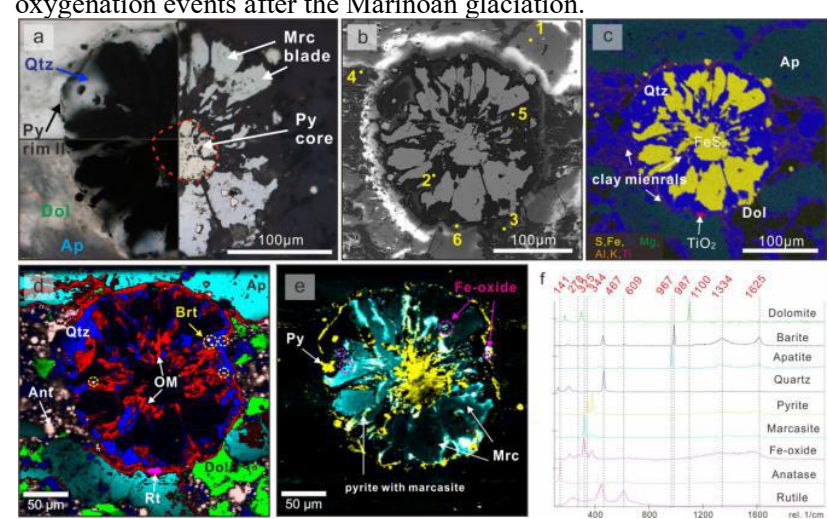

Figure 1: Correlative Raman-SEM analysis on the typical PMR.

a), Plane polarized transmitted light image (left) and reflected light image (right) of the target. b), BSE image; c), EDS map; d), Raman map showing different mineral phases; e), Raman map showing the Fe-bearing phases; f) Raman spectra of the minerals in (d) and (e).

Py, pyrite; Mrc, marcasite; OM, organic matter; Dol, dolomite; Brt, barite; Ap, apatite; Qtz, quartz; Ant, anatase; Rt, rutile.

[1] McFadden et al. (2008) PNAS 9 3197-3202. [2] Sahoo et al. (2012) Nature 489 546-549. [3] Shields-Zhou \& Och (2011) GSA Today 21 4-11. [4] Schoonen \& Barnes (1991a,b,c) GCA 55 1495-1514, 3491-3504. [5] Chandra \& Gerson (2010) Surface Science Reports 65 293-315. [6] Schieber (2011) JSR 81 447-458. 